\title{
Quercus infectoria fruit hulls and galls and female genital disorders
}

\author{
Mohaddese Mahboubi®i
}

\begin{abstract}
Quercus infectoria (Fagaceae family) is traditionally used for treatment of vaginal discharge, prolapse, laxity, and many other female genital disorders. Two important parts of plant including oak fruit hulls (Jaft-E-Baloot) and oak galls (Mazo) are recommended to use for female genital disorders, although, they have many other medicinal applications on skin, urinary and respiratory tract. Tannins as the main ingredients of this genus are the main characteristic for their medicinal properties. Therefore, the aim of this review article was chosen in order to increase the information on Jaft-E-Baloot or Mazo in management of female genital disorders. For preparing the manuscript, the information was gathered from electronics resources (PubMed, Science Direct, Wiley, Magiran, and Springer), books, thesis, etc. up to Feb 2020. Our results exhibited that Jaft-E-Baloot is the thin inner woody hulls of oak fruits, while Mazo is produced in reaction of plant to insect bite. Mazo is a popular compound in different traditional medicines, while Jaft-E-Baloot is known only in Iran. There is any investigation on these two parts in European countries. In Traditional medicine, the same applications are for these two parts especially for female genital disorders, while the majority of modern investigations are on the efficacy of Mazo on cancer, vaginal infections, cervicitis, utero-vaginal prolapse, and there is one clinical study for Jaft-E-Baloot on vaginal laxity. The safety doses of two parts are high and due to their good potency in management of female genital disorders especially vulvovaginitis, they can be the subject of further clinical studies.
\end{abstract}

Keywords: Oak fruit hulls, Jaft-E-Baloot, Oak galls, Mazo, Quercus infectoria, Female, Vaginal infection

\section{Introduction}

Quercus sp. (Fagaceae family) is the forest tree with over 200 species in the world, which they have been distributed in different geographical regions of north hemisphere. The morphology of plant of this genus (Quercus sp.) is depended on the species. Some species of Quercus are tremendous trees and the others are small trees or shrubs. In Iran, there are fifteen species of Quercus, which have long history of medicinal use in Traditional Medicines.

Some species of Quercus have important position in industry and their wood, crock, barks, gums, and galls are used in pharmaceutical and food industries. The distinctive feature of this genus is its high content of condensed and hydrolyzable tannins (50-70\%) [1]. Quercus

Correspondence: mahboubi1357@yahoo.com

Medicinal Plants Research Department, Research and Development,

TabibDaru Pharmaceutical Company, Kashan, Iran sp. fruits are used for cooking bread. The crushed fruit is used for preparing the flour, and then is mixed with water and for sweeting; it remains for 3 days in ambient conditions. The sweet paste is used for cooking bread. This bread is nutritive and a little indigestive [2].

One important member of this genus is Quercus infectoria, which has two important medicinal parts including: galls and fruit hulls with traditional names of "Mazo" and "Jaft-E-Baloot", respectively [3]. "Mazo" or round-shaped galls are formed on leaves, buds and young branches of Quercus sp., especially on different parts of $Q$. infectoria by stinging "Adleria gallae tinctoria" insect, indeed "Mazo" is produced on tree in reaction to insect's sting. "Mazo" has different size and shape and it depends on species [4].

"Jaft-E-Baloot" is the thin dark brown color inner woody hulls of $Q$. infectoria fruits, indeed, after picking the $Q$. infectoria fruits in fall and removing their shells, 
the second skin of fruits is known as "Jaft-E-Baloot" (Fig. 1). From ancient times, Q. infectoria has special location among the Iranian folklore knowledge in management of diseases [5]. In folklore terms, "Jaft-E-Baloot" or "Mazo" have the same application due to the high concentration of tannin (50-70\%) [6], while they are two different parts.

Therefore, due to similar applications of "Jaft-EBaloot" or "Mazo" in traditional medicine and the same source of plant, these two medicinal parts of $Q$. infectoria were the subject of this review article. For preparing of this manuscript, electronics resources (PubMed, Science Direct, Wiley, Magiran, and Springer), books, thesis, etc. were searched up to Feb 2020 by key words of "oak gall", "oak fruit hulls", "Mazo", "Jaft-E-Baloot", "female disorder", "urogenital tract". The main reason for choosing these two parts in management of female disorders was the potency of tannins and these two parts in treatment of women diseases especially diseases related to genital system. Although, there are many other applications for "Jaft-E-Baloot" and "Mazo" in traditional medicine, we decided to focus on female genital disorder. Before everything, the traditional believes on each parts was reviewed.

\section{Jaft-E-Baloot in traditional medicine}

Jaft-E-Baloot is known as astringent compound [7], and its powder in the form of capsule is used orally to tighten stomach, treat diarrhea, and abdominal cramps [8]. Due to high tannins content of Jaft-E-Baloot, it has some biological characteristics such as albumin sedimentation, tissue protective effects, anti-microbial and antituberculosis, wound healing, and astringent effects [7]. The topical or external applications of Jaft-E-Baloot decoctions are higher than internal uses. Jaft-E-Baloot decoctions topically are used in bath for treatment of cancerous ulcers, glands inflammation, infectious ulcers, vaginal discharges, and painful gonorrhea [3]. In Iranian Traditional Medicine, Jaft-E-Baloot powder are applied in treatment of toothache and gingivitis [9] and orally for treatment of menorrhagia [3]. Jaft-E-Baloot powder is used for management of urinary infections in north Khorasan, Iran [10].

\section{Mazoo in traditional medicine}

Mazo is popular compound in Malaysia, which is used for infectious diseases, especially urinary tract infections and for treatment the women during postpartum period [4]. In Unani medicine, Mazo is absorbent, desiccant and used for treatment of wounds, leucorrhea, gingivitis, rectal and uterine prolapse, intestinal ulcers, menorrhagia, chronic diarrhea, asthma, cough, pleurisy, frequent and irregular fevers, intestinal worms, gonorrhea and bleeding disorders [8]. Due to cold and dry temperament of Mazo, it is used topically to cure foul sweating, herpes, ring worms, frostbite, inflammation, infectious skins, eye diseases, and blepharitis. Mazo powder in vinegar is used for treatment of ringworms and alopecia. Mazo powder in the form of ointment is used for rectum prolapse, vaginal laxity and anal diseases. For excessive vaginal discharges, and leucorrhoea, Mazo is used in the form of pessaries [11]. Mazo is orally used for treatment of menorrhagia in Iranian traditional medicine [3]. The Mazo powder as solution or with croton seed oil as suppository is used for management of internal discharges, in south of Iran [2].

According to traditional application of Mazo and JaftE-Baloot in female genital disorders, this review focused on their efficacy in management of these ailments.

\section{Mazo and its effects on vaginal infections}

Vaginal infections are prevalent among women, which are caused by three most important microorganisms:

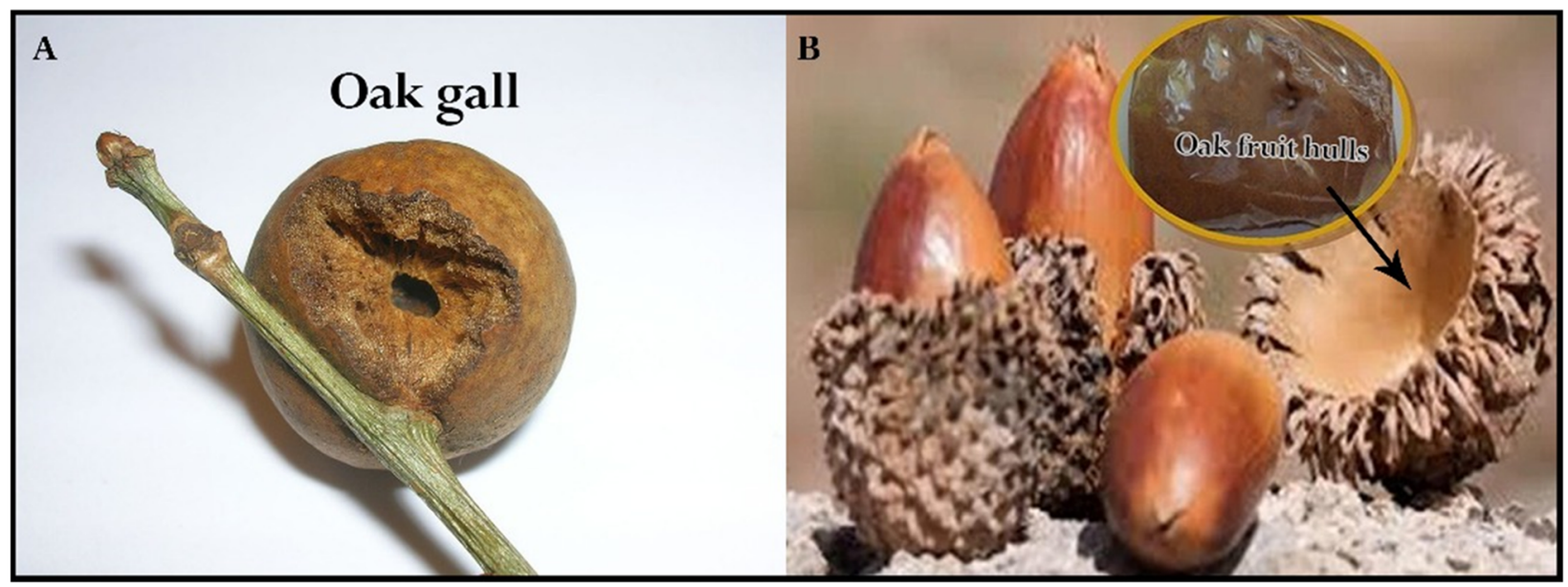

Fig. 1 a Oak gall (Mazo), b Oak fruit hulls (Jaft-E-Baloot) 
Candida albicans, Trichomonas vaginalis and Gardenella vaginalis, although, the other microorganisms may cause the vaginal infections.

Candida sp. as normal flora of the vagina could be the cause of vulvovaginal candidiasis in women under prevailing conditions. Vulvovaginal candidiasis is associated with itching, erythema and vaginal discharge. The high prevalence of disease and its recurrent condition is associated with high economic costs on the society. Candida albicans is the most prevalent cause of vulvovaginal candidiasis [11]. Therefore, the antimicrobial effects of Mazo or Jaft-E-Baloot against the vaginal infection, can confirm its potency in treatment of vaginal discharge according to its traditional believes.

In traditional medicine, "Mazo" and "Jaft", both are used topically for treatment of vaginal discharges [9]. Investigation in modern medicine exhibited that Mazo was the subject of experimental studies for evaluating its potency in vaginal infections. The anti-Candidal effects of Mazo aqueous and methanol extracts were confirmed against Candida sp. (Candida albicans, C. glabrata, C. krusei, C. tropicalis, and C. parapilosis). Candida krusei was the most sensitive species to Mazo extract. Investigation in chemical composition of Mazo methanol and aqueous extracts indicated the presence of $1,2,3$ - benzenetriol (pyrogallol) as the main tannin components [7]. Pyrogallol is a hydroxylated compound with confirmed antimicrobial effect and synergistic effects with antibiotics $[12,13]$.

Trichomoniasis as most common non-viral sexually transmitted infection and as third cause for vulvovaginal infection is caused by protozoan parasite "Trichomonas vaginalis", which is associated with vaginal itching, abdominal pain, and dysuria [14]. Mazo methanol extract inhibited the growth of $T$. vaginalis trophozoites with $\mathrm{IC}_{50}$ values of 21.3 and $3.4 \mu \mathrm{g} / \mathrm{ml}$ after 24 and $48 \mathrm{~h}$, respectively [6].

Gardenella vaginalis is highly prevalent in women and the main cause of vaginal infections [15]. Although, there is no study on antibacterial effects of Mazo against Gardenella vaginalis, the antibacterial effects of Mazo ethanol extract exhibited against methicillin resistant Staphylococcus aureus (MRSA), and it has shown the ethanol extract interfered with autolysins and $\beta$-lactamase enzymes of Staphylococcus aureus [9]. Furthermore, the antibacterial activities of Mazo aqueous and methanol extracts were confirmed against Proteus mirabilis, Proteus vulgaris, Escherichia coli, Klebsiella pneumonia, Staphylococcus saprophyticus, Enterococcus faecalis, Streptococcus agalactiae, and S. pneumonia [16].

Different mechanisms may be responsible for its antimicrobial effects. Tannins showed the antimicrobial effects in different ways. First, the astringent potency of the tannins induces a complexion with bacterial enzymes or substrates. Therefore, the microbial enzymes are inhibited in presence of tannins. Second, tannins may act on microbial membranes and disrupt the cells and third, tannins complex with microbial metal ions and this complex is toxic for microorganisms [17].

The results of experimental studies confirmed the anti-candidal and anti-trichomonal activities of Mazo extracts in vitro conditions, but there is no study on antimicrobial effects of Jaft-E-Baloot against these microorganisms. Jaft-E-Baloot can be the subject of future studies, because due to high concentration of tannins can be introduced as anti-microbial agent.

Clinical trials are needed to evaluate the potency of Mazo or Jaft-E-Baloot in treatment of vaginal infections, especially trichomonasis and candidiasis.

\section{Mazo in treatment of cervicitis}

Cervicitis or cervix inflammation is the common disease of female genital tract, which is associated with acute or chronic inflammation and vaginal discharge [18]. One application of Mazo or Jaft-E-Baloot in traditional medicine is the use of these products in treatment of inflammatory diseases of genital tract.

Investigation in scientific resources exhibited that in one randomized observational study, the intra-vaginal application of Mazo decoction as tampon has been evaluated on subjective or objective parameters of chronic cervicitis of thirty women (18-40 years old). The patients administered the treatment for 7 nights after their menses. Application of Mazo decoction significantly improved all subjective (discharge, low backache, supra pubic pain, dyspareunia, pruritus vulvae, dysuria; $p<0.001$ ) and objectives (discharge, congestion, hypertrophy, nabothian follicles, velvety appearance; $p<0.001)$ parameters in patients with chronic cervicitis [19]. Cervicitis is usually associated with purulent or muco-purulent discharge. Chlamydia trachomatis, Neisseria gonorrhea [20-22], Mycoplasma genitalium, bacterial vaginitis, abnormality of vaginal flora, genital herpes, frequent douching, contraceptives or chemical irritants [22, 23] are the main causes of cervicitis. Therefore, Mazo decoction with antimicrobial activity [9, 14], and anti-inflammatory [24] effects reduces the subjective and objectives parameters of chronic cervicitis. Tannins compounds [24, 25] in Mazo are responsible for antiinflammatory and antimicrobial effects.

The mechanisms, responsible for antimicrobial effects of tannins were explained in last section [17]. Tannins possess anti-inflammatory effects which are positively associated with their antioxidant activities [26]. Tannins in experimental studies modulate the inflammatory cytokine release [27] and inhibit producing nitric oxide (NO) and prostaglandins [28]. It has been found that the antiinflammatory effects of tannins are related to their ability to scavenge the free radicals rather than inhibitory 
effects of on production of $\mathrm{NO}$ and pro-inflammatory cytokines [29].

There is no study on effectiveness of Jaft-E-Baloot on cervicitis, but due to its high content of tannins [25], it can be used for management of female vaginal inflammatory diseases.

\section{Mazo and utero-vaginal prolapses}

Uterine prolapse is the prolapse of posterior and anterior vaginal compartments with unknown etiology. Age, family history, race, high body mass index, vaginal delivery and constipation are the risk factors for development of female uterine prolapse. Uterine prolapse is a recurrent disease which is known by vaginal, urinary, bowel and sexual clinical symptoms [23]. The main treatment for this disorder is gynecological surgery [30]. The potency of Mazo decoction in management of first and second degrees utero-vaginal prolapse was the subject of one randomized single blind placebo control study. In this study, 30 women with first and second degrees of uterovaginal prolapse received $20 \mathrm{~g}$ oral powder of Mazo in the form of decoction for 8 weeks. Mazo decoction reduced the mean score of mass per vaginum, urinary incontinence, VAS (Visual Analogue Scale), PDI-Q, and women's QoL (Quality of Life Scale) scores. The results of this clinical study confirmed the efficacy of Mazo decoction in management of utero-vaginal prolapse as well as quality of life scale in women [31]. The results of this clinical study confirmed the oral administration of Mazo decoction as suitable candidate for management of utero-vaginal prolapse, but it requires performing well designed clinical trials on topical form of Mazo or JaftE-Baloot.

\section{Mazo and their anti-cancer effects}

Cancer as global concern among women is the second leading cause of death in some countries. Breast, cervical, uterine corpus, ovarian, colorectal, liver and lung cancers are prevalent with high incidence among the women [32]. The other important application of Mazo or Jaft-E-Baloot can be its anti-proliferative effects in vitro conditions. Mazo aqueous extract in the form of vaginal cream was evaluated against HeLa cell lines by MTT assay. Then, the effects of this vaginal cream was evaluated for the expression of HPV E6 and E7 protein in HeLa cell lines by Western blot analysis, the histopathological examinations were used to evaluate the toxicity effect of Mazo vaginal cream for 3 weeks on the lower reproductive tract of female rat animal model. The $\mathrm{IC}_{50}$ value of Mazo aqueous extract and its vaginal cream against $\mathrm{HeLa}$ cell lines were $13.9 \pm 2.27$, and $20.8 \pm 1.94 \mu \mathrm{g} / \mathrm{ml}$, respectively, which suppressed the expression of HPV E6 and E7 in HeLa cell lines. No report of inflammation in vaginal mucosa and cervix was reported after 3 weeks daily administration of Mazo vaginal cream [33]. This anti-proliferative effects of Mazo aqueous extract and its vaginal cream may be related to high DPPH radical scavenging activity. The anti-cancer effects of Mazo aqueous or ethanol extract were evaluated against cervical cancer (HeLa), ovarian cancer (Caov-3), normal kidney (Vero) and normal fibroblast (L929) cell lines compared with cisplatin as positive control. Mazo aqueous extract exhibited higher antiproliferative effects towards $\mathrm{HeLa}$ cells $\left(\mathrm{IC}_{50}\right.$ value $=$ $13.64 \pm 2.39 \mu \mathrm{g} / \mathrm{ml}$ ) than that of its ethanol extract. Mazo aqueous extract alters the nuclear morphology and creates the apoptosis through p53-dependant pathway, which is associated with down-regulation $\mathrm{Bcl}-2$ and enhancing the secretion of cytochrome $\mathrm{C}$, which facilitates the apoptosis through caspase- 3 activation. Mazo aqueous extract had no effect on Bax expression [34]. Mazo aqueous extract induced the apoptosis in cancerous cell lines by different mechanisms, which introduce it or Jaft-E-Baloot as topical anticancer agent.

\section{Jaft-E-Baloot and vaginal laxity}

The laxity of vaginal canal alters by hormonal changes, childbirth, weight fluctuations or vaginal infections. Vaginal atrophy, dryness and its relaxation affect the woman's sexual activity, quality of life and their selfconfidence [35]. In traditional medicine, Mazo or Jaft-EBaloot are known as astringent and due to their tissue protective properties are useful for vaginal tissues, therefore, it can be used as vaginal astringent agent in clinics. In spite of the use of Mazo extracts in treatment of different female disorders, Jaft-E-Baloot has been used for clinical studies of vaginal tightness; although Mazo has the good potency in this regard.

In one double blind clinical study on women with complaint of vaginal relaxation $(n=120)$, the efficacy of Jaft-E-Baloot solution (1.5\%, 2, and 2.5\%) was evaluated on personal satisfaction, orgasm, vaginal tightness during intercourse, vaginal loosing feeling, urinary incontinence, feeling the mass in the vagina, the feeling of not reaching to orgasm, feeling the air existence during intercourse, calm feeling after vicinity, and libido before and after interventions. The patients randomly were divided into four groups $(n=30)$ and completed two questionnaires including demographic properties and sexual satisfaction. Then, the patients of each group were recommended to use the Jaft-E-Baloot extract gel at concentrations of $1.5,2$ and $2.5 \%$ or placebo gel. For preparing the final formulation, dried Jaft-E-Baloot methanol (80\%) extract was used in gel formulation. The patients received the vaginal gels for 3 days after menstruation, $5 \mathrm{~min}$ before sexual activity. The patients were evaluated after treatments in regard of adverse effects and sexual satisfaction by questionnaire. The scores were 
divided in five levels of totally satisfied (81-100), fairly satisfied (61-80), no comment (41-60), fairly unsatisfied (21-40), and total unsatisfied (0-20). In this study, the average ages of patients were $36 \pm 5.4$ years old with at least one vaginal delivery. Forty-two patients (35\%) had one case of giving birth by caesarian. Sixty five percent of patients had perinea and vaginal muscle relaxation and 35\% had bladder prolapse. After intervention, there was significant difference in average of sexual satisfaction in patients of Jaft-E-Baloot gel at concentration of $2.5 \%$ compared with the other groups. $60 \%$ of patients in Jaft-E-Baloot gel (2.5\%) experienced a satisfied orgasm, while no patients in other groups experienced the orgasm $(p<0.001)$. The feelings of vaginal tightness were $93 \%, 33 \%$ and $6.7 \%$ for Jaft-E-Baloot gels $2.5 \%, 2 \%$ and $1.5 \%$, respectively. Vaginal dryness as the most prevalent disorder was treated in $86.7 \%, 43.3 \%, 33.3 \%$ and $33.3 \%$ of patients receiving Jaft-E-Baloot gels $2.5 \%, 2 \%, 1.5 \%$ and placebo gel, respectively. The other disorders containing urinary incontinence, the feeling of existence of mass in vagina, not reaching to orgasm, feeling of gas existence during intercourse, calm feeling after intercourse, and libido significantly were different in the group of $2.5 \%$ vaginal gel compared to other groups, respectively $(p<$ $0.0001)$. There was no adverse effects after administration of Jaft-E-Baloot vaginal gels [36]. Thus, Jaft-EBaloot gel tightens the vaginal laxity, and improves the disorders related to vaginal relaxation. So, Jaft-E-Baloot extracts can be topically used in women as sexual and rejuvenation products.

\section{Toxicity and safety of $Q$. infectoria}

Jaft-E-Baloot methanol extract in the form of vaginal gel, 3 days after menstruation was safe and without any adverse effect in human clinical study [36]. Oral daily doses of Mazo aqueous extract $(0,0.125,0.25,0.5$ or $1 \mathrm{~g} / \mathrm{kg} /$ day) on the fertility (premating) and embryonic development (gestation days of 16-20 of pregnancy) in female Sprague Dawley rats showed no mortality, no abnormal behavioral changes (fetuses with normal physical characteristics without congenital malformation) and adverse health status. Pregnancy index, percentages of preimplantation loss, total number of corpora lutea, reproductive organ weights, number of implantation sites, and post-implantation death was not affected from treatments during the pregnancy. $1 \mathrm{~g} / \mathrm{kg} /$ day oak Mazo aqueous extract had no selective toxicity during fertility, pregnancy and embryonic developmental parameters. The dose for its adverse effect level (NOAEL) was 125 $\mathrm{mg} / \mathrm{kg} /$ day [37]. In other study, Mazo ethanol extract was safe up to a maximum dose of $8 \mathrm{~g} / \mathrm{kg}$ body weight of healthy adult albino rats in acute toxicity test [38]. The acute toxicity evaluation of Mazo extract at three doses of $5,7.5$ and $10 \mathrm{~g} / \mathrm{kg}$ for 14 consecutive days showed that maximum tolerate dose was higher than $10 \mathrm{~g} / \mathrm{kg}$. Daily rectal administration of Mazo aqueous extract for 180 days produced no sign of clinical toxicity in rabbits. $10 \mathrm{~g} / \mathrm{kg}$ Mazo aqueous extract is 300 times higher than its daily dose according to traditional medicines [39]. The daily dose of Mazo in traditional medicine is $3-5 \mathrm{~g}$. For reducing the adverse effects of internal uses of Mazo, and Jafe-E-Baloot on chest, Samag-E-Arbi (Acacia arabica gum) is used as corrective compound [2].

\section{Conclusion}

Among different Quercus sp. Q. infectoria is the most popular species for treatment of gynecological disorders. Two different medicinal parts of $Q$. infectoria are used in traditional medicines. The first part is the fruit hulls with Iranian traditional name of "Jaft-E-Baloot "and the other medicinal part is its galls, which is known as "mazo" in Iran and is produced in reaction of young branches to insect bites. The main chemical components, responsible for its biological activities are tannins (50-70\%). Tannins are astringent [7], antimicrobial [40, 41], anti-inflammatory [26] and anti-cancer [42] agents, therefore they are broad extended agents for management of female ailments. Majority of studies have been on Mazo, and there is only one clinical study for Jaft-E-Baloot on vaginal laxity, although, these two medicinal parts have the same biological activities and even Jaft-E-Baloot is cheaper than Mazo. Thus, Jaft-E-Baloot is known in different parts of world and in different traditional systems, while Jaft-EBaloot is known in Iranian Traditional medicine as medicinal plant especially for women. Therefore, the most clinical and experimental studies have been performed on Mazo and the studies on efficacy of Jaft-E-Baloot are belonged to Iranian researchers. Due to the tannin content of Mazo and Jaft-E-Baloot, the indications can be the same. The efficacy of Mazo and Jaft-E-Baloot were confirmed in different ailments of women such as vaginal infections, cervicitis, utero-vaginal prolapse, vaginal laxity, and cancer. The studies on anti-cancer and vaginal infection are experimental research, but its efficacy on cervicitis, utero-vaginal prolapse, and vaginal laxity were confirmed in clinics and animal studies. Designing large clinical studies on efficacy of Jaft-E-Baloot or Mazo extract in combination with some vegetable oils in the form of pessary on vulvovaginal candidiasis is essential according to its traditional believes.

\section{Acknowledgements}

The author is thankful from Mr. A. R. Mazaheri, the director manager of

TabibDaru Pharmaceutical Company for spiritual support during this project.

\section{Author's contributions}

Dr. M. Mahboubi is the sole author of this manuscript. The author(s) read and approved the final manuscript. 


\section{Availability of data and materials}

Not applicable.

\section{Ethics approval and consent to participate}

Not applicable.

\section{Consent for publication}

Not applicable.

\section{Competing interests}

There is no conflict interest.

Received: 11 September 2019 Accepted: 3 July 2020

Published online: 07 July 2020

\section{References}

1. Gardner Z. McGuffin M. American Herbal Products Association's botanical safety handbook: CRC press; 2013.

2. Rakhsha M. Certain curative oak in some settlements in the Zagros region. $J$ Medical History Journal. 2016;3(6):127-37.

3. Zargari A. Medicinal Plants. Tehran: Tehran University Publication; 1997.

4. Grieve M. A modern herbal: Courier Corporation; 2013.

5. Mahmoudvand H, Badparva E, Baharvand Z, Lalehmarzi SHJTB. AntiTrichomonas vaginalis activities and apoptotic effects of some Iranian medicinal plants. Trop Biomed. 2018;35(2):347-53.

6. Ahmad W. Ethnopharmacology of Quercus infectoria galls: a review. Hippocratic J Unani Med. 2016;11:105-18.

7. Ma W, Guo A, Zhang Y, Wang H, Liu Y, Li H. A review on astringency and bitterness perception of tannins in wine. Trends Food Sci Technol. 2014; 40(1):6-19. https://doi.org/10.1016/j.tifs.2014.08.001.

8. Amin G. The most prevalent traditional medicinal plants in Iran. Tehran: Research Deputy of Iran, University of Medical Sciences and Health Services, Research Center for Ethics and Medical History; 2006.

9. Baharuddin NS, Abdullah H, Abdul Wahab WN. Anti-Candida activity of Quercus infectoria gall extracts against Candida species. Journal of pharmacy \& bioallied sciences. 2015;7(1):15-20. https://doi.org/10.4103/ 0975-7406.148742

10. Mosaddegh M, Naghibi F, Moazzeni H, Pirani A, SJJoe E. Ethnobotanical survey of herbal remedies traditionally used in Kohghiluyeh va Boyer Ahmad province of Iran. J Ethnopharmacol. 2012;141(1):80-95.

11. Rathod SD, Klausner JD, Krupp K, Reingold AL, Madhivanan P. Epidemiologic features of Vulvovaginal Candidiasis among reproductive-age women in India. Infect Dis Obstet Gynecol. 2012;2012:859071. https://doi.org/10.1155/ 2012/859071.

12. Tinh TH, Nuidate T, Vuddhakul V, Rodkhum C. Antibacterial activity of Pyrogallol, a polyphenol compound against Vibrio parahaemolyticus isolated from the central region of Thailand. Procedia Chemistry. 2016;18: 162-8. https://doi.org/10.1016/j.proche.2016.01.025.

13. Lima VN, Oliveira-Tintino CDM, Santos ES, Morais LP, Tintino SR, Freitas TS, et al. Antimicrobial and enhancement of the antibiotic activity by phenolic compounds: Gallic acid, caffeic acid and pyrogallol. Microb Pathog. 2016;99: 56-61. https://doi.org/10.1016/j.micpath.2016.08.004.

14. Kissinger P. Epidemiology and treatment of trichomoniasis. Curr Infect Dis Rep. 2015;17(6):484. https://doi.org/10.1007/s11908-015-0484-7.

15. Brown D Jr. Gardnerella vaginalis vaginitis. Am J Obstet Gynecol. 1981; 141(7):846-7. https://doi.org/10.1016/0002-9378(81)90720-1.

16. Chusri S. Voravuthikunchai SJJoam. Detailed studies on Quercus infectoria Olivier (nutgalls) as an alternative treatment for methicillin-resistant Staphylococcus aureus infections. J Appl Microbiol. 2009:106(1):89-96.

17. Chung K-T, Wong TY, Wei C-I, Huang Y-W, Lin Y. Tannins and human health: a review. Crit Rev Food Sci Nutr. 1998;38(6):421-64. https://doi.org/10.1080/ 10408699891274273

18. Kumar A, Kumar A. Chronic cervicitis. J Minim Invasive Gynecol. 2018;25(1): 4-5. https://doi.org/10.1016/j.jmig.2017.02.015.

19. Anees S, Mustafa S. Clinical study for the efficacy of Unani formulation in the Management of Vaginal Discharge Associated with cervicitis (Iltehab-EUnqur Rehm). Int Arch BioMed Clin Res. 2017;3(4):127-9.

20. Taylor SN, Lensing S, Schwebke J, Lillis R, Mena LA, Nelson AL, et al. Prevalence and treatment outcome of cervicitis of unknown etiology. Sex Transm Dis. 2013:40(5):379-85. https://doi.org/10.1097/OLO. Ob013e31828bfcb1.
21. Taylor SN. Cervicitis of unknown etiology. Curr Infect Dis Rep. 2014;16(7): 409. https://doi.org/10.1007/s11908-014-0409-x.

22. Meena V, Bansal CL. Study to evaluate targeted management and Syndromic Management in Women Presenting with abnormal vaginal discharge. J Obstet Gynaecol India. 2016;66(Suppl 1):534-40. https://doi.org/ 10.1007/s13224-016-0879-x

23. Swift S, Woodman P, O'Boyle A, Kahn M, Valley M, Bland D, et al. Pelvic organ support study (POSST): the distribution, clinical definition, and epidemiologic condition of pelvic organ support defects. Am J Obstet Gynecol. 2005;192(3):795-806. https://doi.org/10.1016/j.ajog.2004.10.602.

24. Granica S, Piwowarski JP, Kiss AK. Ellagitannins modulate the inflammatory response of human neutrophils ex vivo. Phytomedicine. 2015;22(14):121522. https://doi.org/10.1016/j.phymed.2015.10.004.

25. Paaver U, Matto V, Raal A. Total tannin content in distinct Quercus robur L. galls. J Med Plants Res. 2010:4(8):702-5.

26. Park $\mathrm{M}, \mathrm{Cho} H$, Jung $\mathrm{H}$, Lee $\mathrm{H}$, Hwang $\mathrm{KT}$. Antioxidant and anti-inflammatory activities of tannin fraction of the extract from black raspberry seeds compared to grape seeds. J Food Biochem. 2014;38(3):259-70.

27. Chacón MR, Ceperuelo-Mallafré V, Maymó-Masip E, Mateo-Sanz JM, Arola L, Guitiérrez C, et al. Grape-seed procyanidins modulate inflammation on human differentiated adipocytes in vitro. Cytokine. 2009;47(2):137-42.

28. Wijesinghe W, Ahn G, Lee W-W, Kang M-C, Kim E-A, Jeon Y-J. Antiinflammatory activity of phlorotannin-rich fermented Ecklonia cava processing by-product extract in lipopolysaccharide-stimulated RAW 264.7 macrophages. J Appl Phycol. 2013;25(4):1207-13.

29. Liu J-B, Ding Y-S, Zhang Y, Chen J-B, Cui B-S, Bai J-Y, et al. Anti-inflammatory hydrolyzable tannins from Myricaria bracteata. J Nat Prod. 2015;78(5):1015-25

30. Doshani A, Teo REC, Mayne CJ, Tincello DG. Uterine prolapse. BMJ (Clinical research ed). 2007;335(7624):819-23. https://doi.org/10.1136/bmj.39356. 604074.BE.

31. Naim M, Begum W. Efficacy of Quercus infectoria Oliv. Galls in the Management of Uterovaginal Prolapse: A Randomized Clinical Trial International Journal of Science and Research. 2017:6(7):1690-4

32. Torre LA, Islami F, Siegel RL, Ward EM, Jemal A. Global Cancer in Women: Burden and Trends. 2017;26(4):444-57. doi:https://doi.org/10.1158/10559965.EPI-16-0858\%J Cancer Epidemiology Biomarkers \&amp; Prevention.

33. MY H, WA WAN. Cytotoxicity effect of Quercus infectoria based vaginal cream on Hela cells and its preliminary in vivo toxicity evaluation towards female rats. Int Med J Malaysia 2018;17(2):746-751.

34. Zulkifly N. Antiproliferative Effevcts of Quercus infectoria galls extract and its mechanism of cell death on cervical Cancer (HELA) cells: Universiti Sains Malaysia; 2015.

35. Karcher C, Sadick N. Vaginal rejuvenation using energy-based devices. Int J Women's Dermatol. 2016:2(3):85-8. https://doi.org/10.1016/j.jiwd.2016.05.003.

36. Lorzadeh N, Sepavand F, Soleimaninezhad M, Kazemirad N. The effect of extract of oak gall for vaginal tightening and rejuvenation in women with vaginal relaxation. Open J Obstet Gynecol. 2016;6(13):879-87.

37. Mohamed Khir NJ. Toxicity evaluation of Quercus infectoria galls aqueous extract on fertility and embryonic development in female Sprague Dawley rats. Malays J Med Sci. 2016;23:144-55.

38. Umachigi S, Jayaveera K, Kumar CA, Kumar G, Kumar DK. Studies on wound healing properties of Quercus infectoria. J Trop J Pharmaceutical Res. 2008; 7(1):913-9.

39. Iminjan M, Amat $\mathrm{N}$, Li X-H, Upur H, Ahmat D, BJPo H. Investigation into the toxicity of traditional uyghur medicine Quercus infectoria galls water extract. PLoS One. 2014;9(3):e90756.

40. Scalbert A. Antimicrobial properties of tannins. Phytochemistry. 1991;30(12): 3875-83. https://doi.org/10.1016/0031-9422(91)83426-L.

41. Redondo LM, Chacana PA, Dominguez JE, Fernandez Miyakawa ME. Perspectives in the use of tannins as alternative to antimicrobial growth promoter factors in poultry. Front Microbiol. 2014;5:118. https://doi.org/10. 3389/fmicb.2014.00118.

42. Li H, Wang Z, Liu Y. Review in the studies on tannins activity of cancer prevention and anticancer. Zhong yao cai Zhongyaocai. 2003;26(6):444-8.

\section{Publisher's Note}

Springer Nature remains neutral with regard to jurisdictional claims in published maps and institutional affiliations. 